\title{
Formulation as a Strategy of Control in Chinese University's Career-Therapy Discourse
}

\author{
$\mathrm{CAO} \mathrm{Yu}$ \\ Beijing Foreign Studies University, Beijing, China \\ Dalian University of Technology, Dalian, China
}

\begin{abstract}
This paper presents a conversation analytic study of formulations used by the therapist and the client in career-therapy environment in a Chinese university. Drawing on Conversation Analysis, the paper describes the features of formulations utilized by the therapist and the client respectively, in terms of initiating patterns, functions, propositional structures, and sentence patterns. By analyzing these features, the paper explores the different distribution of these features between the therapist and the client's formulations, which shows asymmetry. This asymmetrical nature of formulation utilization explains how the therapist and the client construct their identities in the framework of the therapeutic setting by way of formulation.
\end{abstract}

Keywords: formulation, Conversation Analysis, strategy, asymmetry, identity construction, career-therapy discourse

\section{Introduction}

Conversation Analysis is one of the most prominent forms of research in language. Early researchers, such as Harvey Sacks, analyzed daily conversations and initiated "a radical research program designed to investigate the levels of social order that could be revealed in the everyday practice of talking" (Verschueren, 1995, p. 183). As the study in Conversation Analysis develops, the research field extends beyond daily interaction to institutional interaction. "Institutional interaction involves an orientation by at least one of the participants to some core goal, task or identity conventionally associated with the institution in question" (Drew \& Heritage, 1992, p. 22). Through analysis of conversations in different institutional actions, the researchers can reveal the regenerable order under the language use and probe into the interrelationship between language and social order. Psychotherapy discourse is a typical institutional discourse. It happens in a certain environment — psychotherapy setting, in a certain manner-interview, and with certain involvers - therapist and client. Therefore, it is highly ordered and oriented.

Research on psychotherapy discourse has been done by several scholars. Carl Rogers (1942) anticipated the inception of discourse analysis by decades with his pioneering commitment to recording and transcribing therapy sessions. Based on the idea of Rogers, it is believed that through the examination of such recordings, therapy may

CAO Yu, Ph.D. candidate, National Research Center for Foreign Language Education, Beijing Foreign Studies University; assistant professor, School of Foreign Language, Dalian University of Technology. 
become a process based on known and tested techniques. Due to this, a lot of scholars interested in clinical discourse have turned their attention to the investigation of the therapeutic process that close inspection of talk allows. Paul Wachtel in his book Therapeutic Communication: Principles and Effective Practice (1993) introduced therapeutic techniques about how to move from understanding the patient to putting that understanding into words. In his book, he presented an integrative theory of psychological disorder and psychological change, a theory rooted in the psychodynamic tradition while drawing upon insights and discoveries of other approaches as well. He put his focus on nuances of phrasing and meaning which could make crucial differences on the clients. He tried to examine in great detail what the therapist could say that could contribute to the process of healing and change. Robert Russell in the book he edited Language in Psychotherapy (1987) collected several original contributions presenting investigations of therapeutic interaction. "While the methodological strategies and theoretical orientations of these investigations are notably diverse, the utterance-by-utterance analysis of client-therapist dialogue provides a strong commonality of interest and a particular productive perspective from which the process of psychotherapy can be illuminated" (Russell, 1987, p. 252). The articles in this book touched the areas of content category, intersubjective category, extralinguistic category, and linguistic strategies of the psychotherapy discourse. Tom Strong and David Pare in the book Furthering Talk: Advances in the Discursive Therapies (2004) gathered studies exploring conversation as the central resource and medium of therapeutic helping. They made a lot of room for conversational exchanges in order to avoid merely talking about talk and to demonstrate its workings. Moreover, since most researchers of this topic are psychologists, they usually do the research in the perspective of therapy rather than language. Their focus stands on the content of words said by both client and therapist. They try to find out an effective way to evaluate the problem of the client from his words and treat or heal the client by saying words too. In another word, they analyzed the language in therapeutic settings and generalized several language techniques to help the therapists do the therapy. The therapist is put on the position of hearing.

Garfinkel and Sacks (1970) stated that participants may treat some part of the conversation as an occasion to describe that conversation, to explain it, or characterize it, or explicate, or translate, or summarize, or furnish the gist of it, or take note of its accordance with rules, or remark on its departure from rules. That is to say, a member may use some part of the conversation as an occasion to formulate the conversation (Garfinkel \& Sacks, 1970, p. 350). Thus, formulations are a means by which participants may make explicit their sense of what is being talked about; they are a means for constructing an explicit sense of the gist of the talk thus far (Drew, 2003). Garfinkel and Sacks in their classic "On the Formal Structures of Practical Actions" (1970) identified the practical action of formulating. The idea is that people can offer a way of understanding what they are both jointly doing. In their paper, they regarded the natural language as practical actions from the perspective of sociology. They considered indexical properties as ordered properties, which are practical accomplishment of every actual occasion of commonplace speech and conduct. They discussed how to use ethnomethodology to analyze formal structures of practical actions. They also explored formulating a conversation as a feature of the conversation. Paul Drew in his article "Comparative Analysis of Talk-in-Interaction in Different Institutional Settings: A Sketch" (2003) explored formulations in different institutional settings. He stated that "formulations are produced in very specific interactional environments or circumstances in various kinds of institutional discourse, and that they serve to perform specific interactional tasks which vary according to the setting" (Drew, 2003, 
p. 36). He analyzed formulations in ordinary conversation, therapy, radio call-in programs, news interviews, and industrial negotiations and compared the interactional functions and linguistic form of formulations in different settings. Charles Antaki, Rebecca Barnes, and Ivan Leudar in their paper "Diagnostic Formulations in Psychotherapy" (2005) discovered that not all formulations in psychotherapy could be a vehicle for offering a psychological interpretation of the client's circumstances. They offered an analysis of formulations that are diagnostic, that is to say, these formulations are used by the psychotherapist to sharpen, clarify or refine the client's account and make it better able to provide what the psychotherapist needs to know about the client's history and symptoms. They think that "formulations also have the effect of shepherding the client's account towards subsequent therapeutic interpretation" (Antaki, Barnes, \& Leudar, 2005).

In the perspective of social interaction, psychotherapy is an interactional action, in which the therapist helps the client understand himself and his feedback to the environmental factors, which influence him, and help him make sure the meaning, goal, and value of his personal action (JIANG, 2005, p. 12, as cited in Blocher, 1987, p. 13). It is clearly stated here that in the therapeutic process therapist and client are assigned to different identities. The therapist is more a help-provider while the client is more a help-seeker. Besides, due to the shortcomings of the previous studies in therapeutic discourse, the therapist's controlling and directing identity is underestimated, because the therapist is not only a hearer in the process, but more importantly a controller or director. This identity contrast is required and decided by the order in the psychotherapeutic setting. However, it is the therapist and the client, by their language use, that regenerate the particular order and fulfill their different identities in this particular setting. This research puts a focus on one aspect of their language use, that is, formulation to explore how different formulations used by the therapist and the client help construct their different identities. By analyzing features of initiating patterns, functions, propositional structures, and sentence patterns in the therapist's and the client's formulation, along with the asymmetrical distribution of the features between the therapist and the client, this paper shows how formulations, as an effective language strategy, construct the contrast identities in the therapeutic situation.

\section{Setting and Data}

The data analyzed in the paper is collected from several career-therapy interviews in the psychotherapy center in one of China's universities. Career-therapy is one psychotherapy service widely provided in China's universities, whose aim is to help the client understand his expectation of his future and his feedback to the environment now. Based on the expectation and feedback, the therapist can facilitate the client to construct his future career plan. The naturally occurring talk-in-interaction produced in this therapeutic setting was digitally audio-recorded and transcribed. When transcribing, several markers are added to indicate the paralinguistic features of the conversations.

There are four clients involved in the research. They are from the researcher's English-minor class. They are sophomores from three different departments of the university. One requirement is essential. All the clients must be volunteering to do the career-therapy. Those clients are students who consider themselves having confusions regarding their future plan in their mind, and they need the career-therapy to instruct them. In other words, they are not forced to be involved in the research. The psychotherapist is randomly assigned to do the therapy in the psychotherapy center of the university. Among the data, there are 374 formulations found in the transcription of 
the digital recordings. They are marked in bold and italics.

The data is as follows:

Therapist (T); Client (C)

C: yebushi. ni shuo chengji cha ba, yinwei wo ganjue ni pingshi xue de he zuihou kaoshi a, eh no. you say grades bad ba, because I feel you usually study what finally examination a, eh youqi shi daxue xianzai especially is college now

$\mathrm{T}$ :

\section{$\nabla$ kaoshi shi hen nage shenme youdian guochang a}

examination is so that what alittle gothroughthemotions a

C: a dui. ranhou chengji zai nianji yejiushi ershiduo ming

a yes. then grades in grade is about 20 rank

$\mathrm{T}$ : en

en

$\mathrm{C}$ : ye bushi hen cha also not very bad

T: en, ye shuyu hai shiyu zhong shang deng en, also belong almost belong to middle upper class

C: a. qu nian hai naguo jiangxuejin

a. last year also took scholarship

$\mathrm{T}$ : en

en

C: danshi ziji zhimingbai meiyou xuexiao shenmedongxi. \| zhishi chengji zaina eryi but myself not learn anything. just grade there only

$\mathrm{T}$ :

|| erqie yidian xingqu yemeiyou] || and littile interest no

C: dui

yes

C: not like that. As to bad performance, because I felt what you studied and the final examination, especially in college now

$\mathrm{T}$ : examination is a little

C: yes. and I ranked about 20 in my grade

$\mathrm{T}$ : en

C: not so bad

$\mathrm{T}$ : en, it belongs to middle and upper class

C: a. I got the scholarship last year

$\mathrm{T}$ : en

C: but I know I didn't learn anything. only number of my grades

$\mathrm{T}$ : and totally no interest in it

C: yes 


\section{Initiating Patterns}

The initiating pattern of formulation refers to the turn-taking ways by which formulation's turn appears. While the talk that participants to any conversation do is quite variably distributed among participants, one massively evident social organizationally relevant orderliness their talks distribution exhibits is the taking turns at talking (Sacks, 1992). It means that although speakers change, it is true that one party talks at a time in conversation, and that feature of conversation is preserved across variation in the number of parties in conversation, its length, the relative amount each party talks, the relative size of their turns, etc.. In the study of turn-taking organization, the major concern of Sacks, Schegloff, and Jefferson (1974) was how to account for the complex system by which parties engaged in talk manage to take turns at speaking. Turn-taking has two features. Firstly, turn-taking is context sensitive (Psathas, 1995, p. 36). That is to say, turn-taking is related to context and sensitive to whatever is occurring in the context, including the immediately preceding talk. While at the same time, turn-taking is also context free (Psathas, 1995, p. 36). It means that turn-taking does not matter who the speakers are, the times at which they speaks, the setting in which they speak, or the topics about which they speak.

Turn transition is not always smooth. Zimmerman and West (1975) observed the irregularities of transcribed conversations, two sorts of which identified by them were interruption and overlapping. Interruption and overlapping are two kinds of violation of turn-taking system discussed above. In two-party or multiparty interaction, if one party, who is speaking in his turn, is stopped by the other or another party's speaking, this phenomenon is interruption (LIAO, 2003a, p. 175). Interruption requires one condition, that is, one party is stopped in his turn when the other party or another party starts speaking. In two-party or multiparty interaction, when one party is speaking in his turn, the other party or another party starts his turn to speak, and their words are wholly or partially superimposed, this phenomenon is overlapping (LIAO, 2003a, p. 195).

In the data, it is found that the therapist initiated formulations through all the three turn-taking patterns mentioned above.

Excerpt (1)

$1 \mathrm{C}$ : ranhou jiu—xianzai jiushi e- keneng jiushi youdian poguanziposhuaide ganjue and and - now and e-maybe itis alittle letitbepoor likethat

$2 \mathrm{~T}$ : poguanziposhuaide, yinwei xianzai chengji ye hencha? letitbepoor, because now grades also bad?

$3 \mathrm{C}$ : yebushi. ni shuo chengji chaba, yinwei wo ganjue ni pingshi xuede he zuihou kaoshi a, e youqi shi daxue xianza

no. you say grade bad, because I feel you schooltime whatyoulearned with whatexamines, e especially college now

$4 \mathrm{~T}$ :

\section{$\nabla$ kaoshishi hennage shenme youdian guochang a}

examination so what alittle gothrouththemotions a

$5 \mathrm{C}$ : a dui. ranhou chengji zainianji yejiushi ershiduoming

a yes. and grades inmygrade itis top 20

This is the first turn-taking method of initiating a formulation the researcher found in the data. The initiating 
pattern here is interruption. The therapist interrupts the client's words by saying kaoshishi hennage shenme youdian guochang $\boldsymbol{a}$ in the therapist-client's talk-in-interaction. In Excerpt (1), the client is describing his study state, which is "let it be poor" (line 1). In the next turn, the therapist asks the client reason for the state (line 2) and the client explains that (line 3). In the process of the client's talking and before the client's turn ends, the therapist initiates his turn and starts to formulate. This action makes the client stop his on-going talking "e youqi shi daxue xianza" and give up his turn to the therapist. The features of the episode make it satisfy the requirement of interruption. The therapist initiates his formulation by way of interrupting.

Excerpt (2)

$1 \mathrm{~T}$ : shi a, qitade haiyou naxie, huozheshuo ni qujiao jisuanji

yes a, anyother are there, or you gototeach computer

$2 \mathrm{C}$ : jisuanji xianzai zai gaozhong a chuzhong a $\|$ genbenjiu buzhongshi \|

computer now in highschool a juniorschool a absolutely undervalued

//bu shouzhongshi //, duiduidui

$4 \mathrm{C}$ : yige xuexiao jiupei yiliangge laoshi not valued, yesyesyes

one school onyhas oneortwo teachers

This is the second turn-taking method of initiating a formulation the researcher discovered in the data. The initiating pattern here is overlapping. The therapist overlaps what the client is saying with his own words $\boldsymbol{b u}$ shouzhongshi in the therapist-client's talk-in-interaction. In Excerpt (2), the therapist is providing the client with an alternative job possibility, which is teaching computer skills in junior school (line 1). In response, the client is evaluating the therapist's suggestion by saying computer course is undervalued in junior schools (line 2). In the therapist's turn (line 3), the therapist formulates the client's words. However, it is not initiated after the client's turn ends. The therapist's formulation superimposes parts of the words "genbenjiu buzhongshi" in the client's previous turn. This feature meets the requirement of overlapping. The therapist initiates his formulation by way of overlapping.

Excerpt (3)

$1 \mathrm{C}$ : erqie wozhegeren ziwoyueshuli you bijiaocha, yingyufuxiu shi xingqiliu xingqitian shangke, youdeshihou yilan ouer shuigelanjiao

and I self-control also alilltlebad, English-minor is onSaturday Sunday haveclass, sometimes lazy occasionally oversleep

\section{T: en, jingchang kuangke?}

en, frequently absent?

3 C: jingchang *smile

frequently *smile

This is the third turn-taking method of initiating a formulation the researcher observed in the data. The initiating pattern is normal turn-switch. The therapist's formulation jingchang kuangke appears after the client completes his talk in the therapist-client's talk-in-interaction. In Excerpt (3), the client is telling the therapist his personal problem of being absent from class on weekends (line 1). The therapist replies the client by formulating his words. This formulation is different from the above two examples. The therapist's formulation does not 
interrupt nor does it overlap the client's words "erqie wozhegeren ziwoyueshuli you bijiaocha, yingyufuxiu shi xingqiliu xingqitian shangke, youdeshihou yilan ouer shuigelanjiao". The therapist's formulation is made after the completion of the previous client's turn.

\section{Functions}

This section describes the functions of the therapist's formulations, that is, what is the therapist doing by using the formulations in his talk. In How to Do Things With Words (1962/1975), Austin proposed the view that by articulating an utterance a speaker performs an action. Searle (1969) brought forward Austin's research in a more systematic and technical way. In the data, two functions (actions) are observed. They are "articulate the unsaid" and "confirm the said". A formulation of "articulate the unsaid" means a formulation of what has not been said but what the recipient may have meant to say or should have said (Bolden, 2010). A formulation of "confirm the said" means a formulation of confirming requesting a confirmation of what the recipient has said. In Labov and Fanshel's (1977) study, they demonstrated that "in the way they perform their actions, therapist and patient give expression to their proper roles in therapy" (pp. 84-85). In the data of career-therapy setting, the therapist's role is more like an instructor and controller who directs the therapy process. The client is more like a teller and receiver who gets feedback from the therapist. Therefore, the therapist fulfills his role in the therapy process by executing the functions of formulations he uses in his talk.

\section{Excerpt (4)}

$1 \mathrm{C}$ : a - mei, jiushi wowomenwomen zheyidai, wo zaijiali suan $(0.5 \mathrm{~s})$ womanabian shi daoshudier xiaode, wobanabian yeshi, ranhou naxie gegejiejie youjige jiuxianzai ziji zaiwaimian chuangde, zuoshengyi, tingbucuode

a - no, asto my generation, I athome is onmymother'sside is secondyoungest, onmyfather'sside, istoo, and those cousins some now onthemselves outside work, dobusiness, prettygood

$2 \mathrm{~T}$ : en

en

$3 \mathrm{C}$ : e ruguo shiyihou, keneng neng bangshangmang, jiushi gongzuofangmian, danshi wo buxian

eh if infuture, maybe can helpme, asto job, but I not want to

$4 \mathrm{~T}$ : $\boldsymbol{\nabla}$ ni xiang youge wendingde gongzuo?

you want a more stable job

$5 \mathrm{C}: \mathrm{a}-$

yes

The therapist's formulation here functions as "articulate the unsaid". In Excerpt (4), the client is talking about his job preference to the therapist. The client, in the first turn, describes business of his several cousins, in which he shows admiration ("pretty good" in line 1). The therapist's answer (line 2) to this turn proves that he understands the meaning the client would like to express. In the third turn, the client supposes one possibility that his cousins may provide help in his career out of their own business. After this supposition, there follows "but I not want to", which indicates the client's resistance to the businesslike career as his cousins do. The therapist interrupts the client's continuous words with a formulation "you want a more stable job" providing an opposite 
job category to the businesslike one and which is inferable from his resistance. The formulation content is what the client implies but does not articulate. The client's reply to the formulation in the last turn (line 5) testifies the unsaid in the therapist's understanding is what he implies.

Excerpt (5)

$1 \mathrm{C}$ : erqie xianzai yebuyong 60fen, wo suibian nongyixia laoshi dougei 80duofen, wusuowei, dui chengji xianzai meiyou yaoqiu and now notonly 60points, I atmywill doalittle teacher would give morethan80points, idon’tcare, asto grades now no expectation

2 T: en

en

$3 \mathrm{C}$ : dui shangke xianzai ye meiyou shenme yaoqiu, xianzai jiushi qima duideqi zijiba jiushizheba, biye jiukeyile asto class now also no expectation, now itislike atleast satisfy myself itislikethis, graduation isokforme

$4 \mathrm{~T}$ : jiushi neng biye zhege duinilaishuo haibushi wenti

it is can graduate astoyou no problem

$5 \mathrm{C}$ : yinggai bushi wenti, zhishao muqian, zhishao muqian jiushi anzhao zhengchangde zhege guiji fazhan xiaqu dehua, yinggai biye e-biyelunwen xiechulaiule, dabian guole, yinggai busuan tai-taidade wentiba

shouldbe no problem, aslongas now, aslongas now it is follow normal the way forward likethis, should graduate eh—dissertation finish, defense pass, shouldbe no big problem

The therapist's formulation here functions as "confirm the said". In Excerpt (5), the client is talking about his course performance. In the first turn, the client tells the therapist that there is no worry about his course performance because he could easily get a not-so-bad grade (more than 80) (line 1). The therapist receives this information and provides an affirmation (line 2). In the third turn, the client adds that he has no expectation to learn anything from the class and it is OK for him to meet the basic graduation requirement. In the next turn, the therapist formulates the last few turns by saying it is no problem for you to get graduated. This is a natural conclusion which can be drawn from what has been said in the client's two turns. The therapist, in his own words, formulates what has been expressed in the client's words. In the final turn, the client verifies that the formulation is in accordance with what he expresses.

\section{Propositional Structures}

This section describes the propositional structures, which refers to the logical categories the formulations belong to, of the therapist's formulations. Last section explored how the therapist "does things" with his words. Moreover, the researcher observed a phenomena in the data that when fulfill the function of "confirm the said", the therapist's words used in his formulation turn can be classified into two categories- "repeat what exactly the client says" and "express what the client says in his own way". The first category is labeled repetition and the second is labeled reconstruction in this paper. In addition to the two, there is a third category of formulation when the therapist fulfills the function "articulate the unsaid", which is "infer what the client would like to say but does not say". It is labeled inference in this paper. 
Repetition is an easily recognizable category of formulation. It is the category that when doing formulation, the therapist exactly repeats the words already said by the client in the previous turn with no or little change or adaptation. It is usually used to confirm the information provided by the client.

Excerpt (6)

$1 \mathrm{~T}$ : ranhoune? (2s) shangwu shiyou ke shiba?

afterthat? (2s) inthemorning thereis class right?

$2 \mathrm{C}$ : dui, ganggang xiake

yes, just classisover

3 T: ganggang xiake. na wo jiu liaojie yixie nide jiben qingkuang haoba just classisover. and I needto know someof your basic information ok?

4 C: en xing

eh yes

In Excerpt (6), the therapist is asking the reason of the client's later arrival. The therapist formulates what the client says with the sentence "just class is over" (line 3). This formulation is exactly the same with the client's words "just class is over" (line 2). The therapist does the formulation by repeating the client's words to confirm the information he receives from the client. The client's next turn "yes" testifies the confirmation.

Reconstruction is another way that the therapist formulates the client's words. The therapist re-expresses what has been said by the client in the previous client's turn in his own words. The therapist re-organizes the client's language and keeps the meaning unchanged. It is frequently used to confirm the information given by the client as the formulation of repetition does.

Excerpt (7)

$1 \mathrm{C}$ : yinwei wo meiyou xuedao dongxi, faxu because I don't learn anything, Ifeltafraid

$2 \mathrm{~T}$ : jiu youdian pa thatis alittle fearful

3 C: dui, jiushi haipa yes, itis fearful

In Excerpt (7), the client is describing his feeling of lack of knowledge. The therapist formulates the client's turn "Ifeltafraid" (line 1) with the sentence "alittle fearful" (line 2). This formulation, instead of repeating the client's words, uses some other words. However, the meaning keeps unchanged. The therapist does the formulation by reconstructing the client's words to confirm the information given by the client. This is testified by the client's next turn "yes".

There is a third way of therapist's formulating. When doing formulation, the therapist may infer the meaning in the client's mind according to what has been said by the client. This kind of formulations is inference.

Excerpt (8)

$1 \mathrm{C}$ : wo fuqin shi-jiu yiming gongrenba, muqin zajiali meiyou gongzuo my father is - is a factoryworker, mother athome no job

$2 \mathrm{~T}$ : na zhege jingji tiaojian yiban so the financial situation not-so-good 
$3 \mathrm{C}$ : en, yiban

yes, not-so-good

In Excerpt (8), the therapist formulates what the client has said in the previous turn with the sentence "the financial situation not-so-good" (line 2). The client does not articulate this information. From the information provided by the client that his father is a factory worker and his mother is unemployed, the therapist infers that family income of the client should not be high. The therapist does the formulation by articulating the unsaid but inferable information. The client's next turn "yes" confirms the unsaid inference is valid.

It is obvious that in terms of function and propositional structure, there is a corresponding relationship between the two factors, as shown in Table 1.

Table 1

Coresponding Relationship Between Function and Propositional Structure

\begin{tabular}{|l|l|}
\hline Functions & Propositional structures \\
\hline \multirow{2}{*}{ To confirm } & Reconstruction \\
\cline { 2 - 3 } & Repetition \\
\hline To infer & Inference \\
\hline
\end{tabular}

Table 1 shows that the function of infer corresponds with the propositional structure of inference and the function of confirm corresponds with the propositional structure of reconstruction and/or repetition.

\section{Client's Formulation}

There are two subjects in the process of career-therapy - the therapist and the client. In sections above, only the formulations made by the therapist have been analyzed. In the following, the formulations made by the client will be analyzed.

The process of career-therapy consists of three parts. In the first part, the therapist asks questions to acquire background information of the client. In the second part, the therapist talks with the client to figure out the psychological problems of the client. The therapist gives advice in the third part. Through the analysis of all the data, the client's formulations are only made in part three of the therapy process. When the therapist gives an advice, the client may do formulation to this advice.

Excerpt (9)

$1 \mathrm{~T}$ : suoyi zhege gongwuyuan wo juede haishi keyi zhunbei zhunbei. (1s) || yinwei || xianzai gongwuyuan dui nahaizi laishuo yinggai shige

so the civilservant I feel is worth preparing preparing, because now civilservant asto girls asto shouldbe a

$2 \mathrm{C}$ :

$\|$ en $\|$

$\boldsymbol{\nabla}$ hen buhao $\perp$ hen bucuode yige chulu ba very bad very good a choice ba

3 T: dui, ta shouru bijiao feichang wending, erqie shehui diwei ye bijiao gao

yes, its income alittle very stable, and social position also very high

In Excerpt (9), the therapist is giving career advice to the client (line 1). In the next turn (line 2), the client interrupts the therapist's words with the sentence very bad very good a choice ba, which is a formulation to the therapist's advice. It is used to infer the therapist's inferable but unarticulated meaning. From the therapist's 
words because now civilservant asto girls asto shouldbe a, the client acquires the therapist's meaning. Before the therapist ends his turn, the client interrupts him and provides the information. It belongs to the propositional structure of inference.

Excerpt (10)

$1 \mathrm{~T}$ : ni keyi zhao tamen liaojie yixia, liaojie yixia jiushuo nage pingchang $\|$ shiyao zuo xieshenme you can ask them tell alittle, tell alittle that about usually should do what

2 C: $\quad$ || shenghuo shi shenme yangde II life is what like

$3 \mathrm{~T}$ : dui, jiushuo yanjiusheng ta daodi yao zuo xieshenme shiqing, tebieshi dili fangxiangde yanjiusheng

yes, postgrads they onearth should do what things, especially geography study postgrads

In Excerpt (10), the therapist is advising the client to get information of his possible future career (line 1). In the client's turn, he overlaps with the therapist when articulating the sentence life is what like. This sentence is the formulation made by the client to the therapist's words should do what. It is used to infer the therapist's not-already-articulated meaning. It belongs to the propositional structure of inference.

Excerpt (11)

$1 \mathrm{~T}$ : na wo juede ni shikeyi jiushi ba ni yuanlai nage xiangfa naqu zuo, kao nage qingzangban so I think you can DM put your original idea into doing, passtheexam that Tibetclass

$2 \mathrm{C}$ : jiu kao nage yanjiusheng

thatis passtheexam that postgrad

$3 \mathrm{~T}$ : en

yes

In Excerpt (11), the therapist is giving advice if the client's future career choice (line 1). The client's words thatis passtheexam that postgrad (line 2) is the formulation to the therapist's advice so I think you can DM put your original idea into doing, passtheexam that Tibetclass. It is used to confirm what has been said by the therapist in his previous turn. The client makes this formulation after the therapist finishes his turn. It belongs to the propositional structure of reconstruction.

After analyzing all the formulations made by the client in the process of career-therapy, it is found a corresponding relationship between function and propositional structure and it is of the same feature as shown in Table 1 of the formulations made by the therapist.

\section{Asymmetry: Distribution of the Therapist's and the Client's Formulations}

Distribution refers to the fact that the amount, in terms of number, of all kinds of formulations in different part of the process of the career-therapy is not average. Based on the analysis in the above sections, ratio will be used to show the distribution of different formulations. The phenomenon of distribution can reveal a very important feature of formulations in career-therapy discourse, that is, asymmetry. Asymmetry means formulations, in terms of types, initiating patterns, functions, and subjects, are asymmetric. Certain formulations are used in the discourse much more frequently than others. Due to the asymmetry, the distinguishing features of formulations made by the therapist and the client respectively in the process of career-therapy can be explored.

Through the analysis of the therapist's formulations, it is known that there are several categories of 
formulations in terms of initiating patterns, functions and propositional structures as shown in Table 2 .

Table 2

Category of Formulations Made by the Therapist

\begin{tabular}{|l|l|}
\hline Initiating patterns & Interruption, overlapping, complete turn-exchange \\
\hline Functions & Infer, confirm \\
\hline Propositional structures & Inference, reconstruction, repetition \\
\hline
\end{tabular}

Those different categories of formulations are not in a balanced status in the process of career-therapy. They are of asymmetry. Certain category of formulations is made more frequently than the others. Through the analysis of all the transcribed data, Tables 3-5 can show the asymmetric features of formulations in the process of career-therapy discourse:

Table 3

Asymmetry of Formulations in Terms of Initiating Patterns

\begin{tabular}{lc}
\hline Initiating pattern & Ratio (initiating pattern/totality) \\
\hline Interruption & $56 / 374$ \\
Overlapping & $31 / 374$ \\
Complete turn-exchange & $287 / 374$ \\
\hline
\end{tabular}

Table 4

Asymmetry of Formulations in Terms of Functions

\begin{tabular}{ll}
\hline Function & Ratio (function/totality) \\
\hline Infer & $148 / 374$ \\
Confirm & $226 / 374$ \\
\hline
\end{tabular}

Table 5

Asymmetry of Formulations in Terms of Propositional Structures

\begin{tabular}{lc}
\hline Propositional structure & Ratio (propositional structure/totality) \\
\hline Inference & $148 / 374$ \\
Reconstruction & $67 / 374$ \\
Repetition & $159 / 374$ \\
\hline
\end{tabular}

According to the data, there are 374 formulations in all the six pieces of transcription. Table 3 shows the distribution of formulations in terms of initiating patterns. There are 56 formulations initiated in the way of interruption; 31 formulations initiated in the way of overlapping; 287 formulations initiated in the way of complete turn-exchange. The statistics states that most formulations are made in a complete turn exchange in the therapist-client's talk-in-interaction. The psychotherapist does not frequently interrupt or overlap with the client when he is speaking. But it does happen sometimes. Most of time, the two subjects exchange the turn smoothly. Table 4 shows the distribution of formulations in terms of functions. It clearly shows that formulations of confirm, which are 226, are more than those of infer, which are 148 . However, the difference is not dramatic. Generally speaking, the two functions are in balance. Table 5 shows the distribution of formulations in terms of propositional structures. The two most frequently articulated categories are inference and repetition. There are 148 and 159 respectively. The propositional structure of inference corresponds with the function of predicting. The propositional 
structure of repetition corresponds with the function of confirm. The amount of reconstruction and repetition is 67 and 159 respectively, which also corresponds with the function of confirm, whose totality is 226.

From the analysis of the client's formulations, it is clearly shown that there are obvious differences between the formulations of the psychotherapist and the client as shown in Table 6.

Table 6

Difference of Formulations Between the Client and the Therapist

\begin{tabular}{llll}
\hline Subjects & $\begin{array}{l}\text { Amount of } \\
\text { formulations }\end{array}$ & $\begin{array}{l}\text { Main functions (propositional structures of formulations) } \\
\text { infer: confirm (inference, repetition and/or reconstruction) }\end{array}$ & Time \\
\hline Therapist & 374 & $148: 226$ & $\begin{array}{l}\text { All over the process of the } \\
\text { therapy }\end{array}$ \\
Client & 20 & $6: 14$ & Advice-giving part \\
\hline
\end{tabular}

In terms of amount, the client's formulations are much fewer than the psychotherapist's. In terms of time when formulations are made, the client only does so in the advice-giving part of the therapy process. In terms of functions, overall in the 20 formulations, there are 14 formulations functioning as confirms and only six formulations functioning as infer. In terms of initiating pattern, only two formulations of the initiating patterns of interruption and overlap respectively are observed in the data. All the other formulations made by the client are done after the therapist finishes his turn. In terms of propositional structure, six out of 20 formulations made by the client belong to inference. The others belong to repetition and/or reconstruction.

\section{Conclusion}

It is clearly shown that the amount of the psychotherapist's formulations is dramatically higher than that of the client's. The two functions of the therapist's formulations are nearly in balance. And the therapist does formulations all over the whole process of the career-therapy. However, most of the client's formulations function as confirms. And the client only does formulation in the advice-giving part of the career-therapy. Due to the limited amount and time of the client's formulations, it can be said that the client almost only does formulations to accept the therapist's advice while the therapist does formulations to infer and confirm the client's information. In career-therapy, inferences and confirms are directive. The therapist uses inferences to bring up hypothesis in his mind. The hypothesis can direct the process of the career-therapy. The therapist also uses confirms to verify his hypothesis and reinforce the process of the career-therapy. By using directives, a speaker proposes to exert control over other conversational participant (Goodwin, 1990). Therefore, the psychotherapist is the decisive role in the career-therapy process.

Formulations have attracted interest in Conversation Analysis since Sack's pioneering work on group therapy in his Lectures on Conversation (1992). The study reported here adds to the understanding of initiating patterns, functions, propositional structures, and distribution of formulations in career-therapy discourse. It is found that there are two main functions of the therapist's formulations - infer and confirm; there are three propositional structures - inference, reconstruction, and repetition. It is also found certain correspondence between functions and propositional structures. Based on the above analysis, the distribution of therapist's formulations has been tentatively explored. And the client's formulations have also been analyzed. By comparing the therapist's and the client's formulations, efforts are made to probe into the relationship in the process of 
career-therapy. Based on the comparison, it proves that the therapist plays a directive and decisive role in the process of career-therapy while client plays a cooperative role. Due to the limitation of the data, the research may be extended to different kinds of therapy situations or even other institutional settings.

\section{References}

Antaki, C., Barnes, R., \& Leudar, I. (2005). Diagnostic formulations in psychotherapy. Discourse Studies, (6), 627-647.

Austin, J. (1975). How to do things with words. Oxford: Oxford University Press.

Blocher, D. H. (1987). The professional counselor. New York, NY: Macmillan.

Bolden, G. B. (2010). Articulating the unsaid via and-prefaced formulations of others talk. Discourse Studies, 12(1), 5-32.

Brewer, D. J. (2000). Ethnomethodology. Buckingham: Open University Press.

Clegg, S. (1993). Narrative, power and social theory. In D. K. Mumby (Ed.), Narrative and social control: Critical perspectives (pp. 15-45). London: SAGE.

Dahl, R. (1961). Who governs? Democracy and power in American city. New Haven, CT: Yale University Press.

Drew, P. (2003). Comparative analysis of talk-in-interaction in different institutional settings: A sketch. In P. J. Glenn, C. D. LeBaron, \& M. J. Mahwah (Eds.), Studies in language and social interaction: In honor of Robert Hopper (pp. 293-308). Mahwah, NJ: Erlbaum.

Drew, P., \& Heritage, J. (1992). Talk at work: Interaction in institutional settings. Cambridge: Cambridge University Press.

Fairclough, N. (1989). Language and power. New York, NY: Longman Group.

Fairclough, N. (1992). Discourse and social change. Cambridge: Polity Press.

Fairclough, N., \& Wodak, R. (1997). Critical discourse analysis. In T. A. van Dijk (Ed.), Discourse as social interaction (pp. 258-284). London: SAGE Publications Ltd..

Foucault, M. (1980). Power/Knowledge. New York, NY: Patheon.

Garfinkel, H. (1967). Studies in ethnomethodology. Englewood Cliffs, New Jersey: Prentice Hall.

Garfinkel, H., \& Sacks, H. (1970). On the formal structures of practical actions. In J. D. Mckinney \& E. A. Tiryakan (Eds.), Theoretical sociology. New York, NY: Appleton-Century Crofts.

Goodwin, M. H. (1990). He-said-she-said: Talk as social organization among black children. Bloomingtion, IN: Indiana University Press.

Have, P. (1999). Doing conversation analysis: A practical guide. London: SAGE Publications Ltd..

JIANG, G. R. (2005). Theory and practice of psychotherapy. Beijing: Higher Education Press.

Jucker, H. A., \& Ziv, Y. (1998). Discourse markers: Descriptive and theory. Amsterdam: John Benjamin's Publish Company.

Labov, W., \& Fanshel, D. (1977). Therapeutic discourse: Psychotherapy as conversation. New York: Academic Press.

LIAO, M. Z. (2003a). Courtroom questions responses and their interaction. Beijing: Law Press.

LIAO, M. Z. (2003b). Structure of interaction in Chinese courtroom. Language Science, (5), 77-89.

LIAO, M. Z. (2006). A study of formulation in Chinese courtroom discourse. Foreign Language, (1), 1-13.

Psathas, G. (1995). Conversation analysis: The study of talk-in-interaction. Thousand Oaks: SAGE Publications Inc..

Rogers, C. R. (1942). The use of electrically recorded interviews in improving psychotherapeutic techniques. American Journal of Orthopsychiatry, (12), 429-434.

Russell, L. R. (1987). Language in psychotherapy. New York, NY: Plenum Press.

Sack, H., Schegloff, E. A., \& Jefferson, G. (1974). A simplest systematics for the organization of turn-taking for conversation. Language, (4), 696-735.

Sacks, H. (1992). Lectures on conversation. Oxford: Basil Blackwell.

Strong, T., \& Pare, D. (2004). Furthering talk: Advances in the discursive therapies. New York, NY: Kluwer Academic/Plenum Publishers.

Thornborrow, J. (2002). Power talk: Language and interaction in institutional discourse. Harlow: Pearson Education.

Verschueren, J. (1995). Handbook of pragmatics. Amsterdam: John Benjamin's Publish Company.

Wachtel, L. P. (1993). Therapeutic communication: Principles and effective practice. New York, NY: The Guilford Press. 